\title{
Improving Adolescents' Attitudes towards Persons with Disabilities: An Intervention Study in Secondary Education
}

\author{
Julián Álvarez-Delgado *, Benito León-del-Barco *(D), María-Isabel Polo-del-Río (D), Víctor-María López-Ramos $\mathbb{D}$ \\ and Santiago Mendo-Lázaro $\mathbb{D}$
}

Citation: Álvarez-Delgado, J.; León-del-Barco, B.; Polo-del-Río, M.-I.; López-Ramos, V.-M.; Mendo-Lázaro, S. Improving Adolescents' Attitudes towards Persons with Disabilities: An Intervention Study in Secondary Education. Sustainability 2021, 13 , 4545. https://doi.org/10.3390/ su13084545

Academic Editors: Luis Ortiz Jiménez and Marc A. Rosen

Received: 26 February 2021

Accepted: 15 April 2021

Published: 19 April 2021

Publisher's Note: MDPI stays neutral with regard to jurisdictional claims in published maps and institutional affiliations.

Copyright: (c) 2021 by the authors. Licensee MDPI, Basel, Switzerland. This article is an open access article distributed under the terms and conditions of the Creative Commons Attribution (CC BY) license (https:/ / creativecommons.org/licenses/by/ $4.0 /)$.
Department of Psychology, Faculty of Teacher Training College, University of Extremadura, 10071 Caceres, Spain; mabelpdrio@unex.es (M.-I.P.-d.-R.); vmlopez@unex.es (V.-M.L.-R.); smendo@unex.es (S.M.-L.)

* Correspondence: jad@unex.es (J.Á.-D.); bleon@unex.es (B.L.-d.-B.)

\begin{abstract}
The relationship of disabled persons with their environment is fundamental. Attitudes towards them, understood as the social constructs of those around them, play a key role in a person's development and future, as they are one of the fundamental elements that can facilitate or hinder the inclusion process. Our work examines the need to implement educational and awarenessraising actions and programs that contemplate intervention strategies based on education and direct contact with disabled persons. The main objective of the study was to analyze the effect of a Program for Changing Attitudes towards Persons with Disabilities on a group of secondary school students (11 to 15 years of age), assigning 770 to the experimental group and 105 to the control group. The evaluation instrument used was the "Brief Questionnaire of Attitudes towards Persons with Disabilities for Adolescents, CBAD-12A". The results have demonstrated the efficacy of the intervention for the experimental group, as it was possible to attribute the changes in attitude to the effect of the Program. Specifically, an improvement in attitudes was found in all three factors of the questionnaire (Acceptance-Rejection, Competence and Opportunity) after the intervention.
\end{abstract}

Keywords: adolescent; attitudes; disability; intervention; secondary education

\section{Introduction}

Among the objectives of the CRPD-Convention on the Rights of Persons with Disabilities(2006) are the promotion, protection and achievement of equality concerning all the human rights and fundamental liberties of disabled persons, as well as promoting respect for their inherent dignity. This Convention reflects an important change in the understanding of disability and the world's responses to this problem [1]. Spain's education system is one of the principal guarantors of education and the educational context, understood as a privileged space from which to encourage change, as set out in the CRPD [2]. The principles of inclusion and equality set out in the education laws from 2006 to 2020 are the basis of an education for all students without discrimination, giving special attention to those with any kind of disability, in accordance with the terms established in the Convention on the Rights of Persons with a Disability [3]. The number of students with a disability in Spain's general, nonuniversity education system in the academic year 2017-2018 was 219,720 students with special educational needs derived from a disability. Of these, 36,512 (16.6\% of the total) were in Special Education Centers, while 183,208 (83.4\% of the total) were integrated in ordinary centers at different stages of the education system [2].

Disability itself is approached from the basis of the social model of Disability, not only as an attribute of the person but also as the interaction of a set of conditions, many of which are created by the social setting [4-7]. From the ecological and contextual perspective, the analysis of the interaction between the person with a disability and his/her environment is fundamental [8].

A person's functions and disability are conceived as a dynamic interaction between her/his state of health and the contextual factors, which also include environmental and 
personal factors that hinder a full and effective social participation on an equal footing with others [9-11]. Outstanding in importance among the said factors are attitudes towards the disabled collective as a determining relational and environmental factor that can facilitate or hinder the process of inclusion in society [1,12].

If the relationship of disabled persons with their surroundings is vital, the attitudes, understood as the social constructs of those around them, also play a key role in the development and future of the person. This is because they make up one of the fundamental elements that either facilitates or hinders the collective's process of inclusion [13-16].

The attitude construct is considered to be a learnt predisposition to consistently respond to objects, persons or groups of persons and situations either favorably or unfavorably [17]. The attitude construct is built upon three components: the cognitive, made up of beliefs; the affective, made up of emotions; and the behavioral, made up of the tendency or predisposition to act $[18,19]$. On the basis of these three components, society still shows them in the form of disaffected social beliefs and their associated behaviors, predominantly negative and pejorative attitudes which stigmatize disabled persons [20,21]. Depending on whether the attitudes are positive or negative, they will either favor or reduce the possibility for inclusion on a social, family or individual level [22-25].

For all the above, these attitudes are considered to be one of the most powerful barriers against the acceptance of persons with a disability, as well as one of the greatest obstacles in the path towards inclusion $[1,15,16]$.

One factor that may positively influence a change in attitudes towards disabled persons is to experience situations where one comes into direct contact with them [26,27]. In this sense, it is relevant to mention Allport's contact theory [28], which postulates how contact between persons can modify attitudes. Several works of research confirm that prior, direct contact with persons with a disability can improve attitudes towards this collective and it is considered to be one of the most effective techniques in attitude changing programs [29-31].

The effectiveness of the attitude change through the contact technique is because it facilitates the discovery of the positive attributes of disabled persons by means of a structured contact, focused on positive interactions that allow the disabled person's potential to be recognized, generating better adjusted expectations and helping to eliminate barriers and prejudices towards them [32,33].

Certain document reviews and attitude changing program analyses carried out in educational contexts analyzed the procedures used in their implementation. In addition to social contact, the most commonly used strategies in attitude reorientation programs were education, information and cooperative work teams. They were also the ones that showed the greatest effectiveness [34-36].

If education is the initial step to promoting positive attitudes towards persons with a disability [22], aiming to carry out intervention programs whose objective is a change of attitudes based on information that reflects reality can result in sufficient cognitive dissonance in the participants as to bring about a re-evaluation of their attitudes [37]. Respect for differences, tolerance, and the acceptance of disabled persons increase when encouragement is provided to get to know and understand the collective from the point of view of empathy and affective rapprochement [38-40]. This takes on greater value if we focus on the importance of achieving changes in attitudes in the social order that allow spaces to be opened, generating greater participation and opportunities for social coexistence [34].

Our Study

For all the above, this study raises the need to include awareness-raising actions and educational programs that contemplate education alongside direct contact with disabled persons as intervention strategies, quite apart from the informative side, which is rightly considered to be the cornerstone of any program that aims to change attitudes. The reason is that mere information as a technique is not sufficient to change attitudes [41-43]. 
It is important to concentrate such actions and programs on the youngest students, on children and adolescents, as these are the stages at which persons develop and consolidate their attitudes. It is precisely during these years when a lack of knowledge concerning disability can negatively affect their attitudes, and when the interventions aimed at modifying and molding them are more successful [44-47].

Starting from this reality, adopting measures at the different levels of the educational system is considered to be a priority. Such measures can encourage positive attitudes towards and respect for persons with a disability, dismantling the stereotypes and prejudices that continue to hinder their full inclusion in society [11,47]. The need to modify attitudes in order to encourage a change of perspective, based on inclusion instead of discrimination, is considered and demanded by both specific works in this field and the political, educational and social institutions [11,25,35,48,49]. At present, this need has sufficient support from science and research-based data concerning the possibility of attitude changes towards this collective; however, it still remains a sphere of intervention that receives little publicity [43,50-53].

The present study aims to analyze the effect of the Program for Changing Attitudes towards Disability (PCAD) in secondary school students (ESO). This program is developed through a methodology based on structured interventions with disabled monitors, using awareness, informative and contact techniques.

\section{Materials and Methods}

\subsection{Participants}

The number of participants was determined on the basis of the 43,389 students in secondary education (ESO) in the Region of Extremadura (Spain) during the academic year 2018-2019, considering a sample error of 3.5\% and a confidence interval of $96 \%$. The total sample was made up of 875 students from ESO belonging to 20 state or direct grant schools. These centers were selected at random by means of a cluster sampling from a total of 120 centers. As for representativeness in ESO, 32.5\% of the students were in their first year, $24.7 \%$ in their second year, $20.8 \%$ in third, and $22 \%$ in fourth. $52 \%$ were female and $48 \%$ male, between 12 and 16 years of age $(M=13.40 ; \mathrm{SD}=1.37)$. The experimental group consisted of 770 students (1st year of ESO $=252 ; 2$ nd year of ESO $=191$; 3rd = 160; 4 th $=167)$ and the control group of 105 students $(1$ st $=32 ; 2$ nd $=26$; 3rd $=22 ; 4$ th $=25)$. There were no significant differences between the experimental and control groups with respect to age, $\mathrm{t}(873)=0.636, p=0.525$; or gender, $\chi^{2}(1)=2.370, p=0.124$.

\subsection{Instrument}

"Brief Questionnaire on Attitudes towards Persons with a Disability for Adolescents" (CBAD-12A). The questionnaire CBAD-12A [53] is made up of 12 items grouped into three factors of four items each. The first factor is called "Acceptance/rejection" and mainly evaluates the components of the attitude related to prejudice and the behavioral response derived from it; the second factor is called "Competence/limitation" and mainly analyzes the stereotypes understood as social constructs (beliefs) based on generalizations derived from erroneous or incomplete information concerning disabled persons; finally, the third factor is called "Equality of opportunities" and analyzes the attitudes understood as rights and how the stereotypes and prejudices towards this collective influence the achievement or not of the said rights by persons with a disability. The format of the responses is a Likert-type scale with five options in which 1 means "totally disagree" and 5 "totally agree". In this sense, higher scores in the three factors indicate more negative attitudes towards persons with a disability, i.e., attitudes that suffer from more stereotypes, prejudice and discriminatory behavior patterns towards the said collective.

In this present study, the reliability ratings for the different factors were: acceptance/rejection, Cronbach's Alpha $(\alpha=0.62)$ and McDonald's omega $(\Omega=0.64)$; competence/limitation ( $\alpha=0.57, \Omega=0.57)$; equality of opportunities $(\alpha=0.54, \Omega=0.54)$. 
To confirm whether the model found in the original validation study [53] adequately fit our data; we have used the goodness of fit indices described in Table 1. As can be seen, the model is found to be adequate and the goodness of fit indices optimal, showing evidence of both sufficient reliability and validity for the generalization of our results.

Table 1. Goodness of fit indices for the proposed model, Questionnaire (CBAD-12A [53]).

\begin{tabular}{ccccccccc}
\hline Model & $\chi^{2}$ & $\chi^{2} / \mathbf{d f}$ & GFI & IFI & TLI & CFI & MRSR & AMRSR \\
\hline 3 factors & 140.767 & 2.760 & 0.972 & 0.931 & 0.909 & 0.930 & 0.042 & 0.046 \\
\hline
\end{tabular}

Notes: $\chi^{2}=$ Chi square statistic; $\chi^{2} / \mathrm{df}=$ Chi square divided by the degrees of freedom; GFI = Goodness of fit index; AGFI = Adjusted goodness of fit index; IFI = Incremental goodness of fit index; TLI = Tucker-Lewis index; $\mathrm{CFI}=$ Comparative goodness of fit index; $\mathrm{MRSR}=$ Mean residual square root; AMRSR $=$ Approximate mean residual square root.

\subsection{Procedure}

The study was carried out in the various centers selected for the intervention, during a school term over seven weeks in school hours. The centers were asked to complete an informed consent for the research, a document requesting that the Educational Center expressly accepts its participation in the research.

The main objective of the Program for Changing Attitudes towards Disability (hereafter PCAD) is to promote a change in the way the collective is viewed through accurate information, situating students in the place of disabled persons so they can empathize with them and transmit the reality of the "non" recognition of fundamental rights which stops them from achieving the same goals as the rest of society.

Our study had three phases. The first took place two weeks before the intervention and consisted of administering the questionnaire CBAD-12A. Qualified personnel went to the centers at a previously arranged day and time to coincide with a tutorial class in order to supervise the completion of the questionnaire, attending to all the doubts that the students might have. The tutorial time was chosen as it meant the task would take place in a relaxed atmosphere and in the presence of the class tutor. The presentation, completion and collection of the questionnaire took about $40 \mathrm{~min}$.

In the second phase, the intervention itself took place using the PCAD, which was applied by a group of ten monitors with a physical and organic disability who had been previously trained in the program's objectives and contents. Each intervention in an educational center was given by a pair of monitors with the same class group.

The application of the PCAD consists of three sessions of $90 \mathrm{~min}$, one session per week. The first session consists of the presentation of the program and the monitors who are to lead it. The monitors then start a debate-discussion with the class group to detect the students' perceptions concerning disabled persons, asking them what attitudes they think society has about disability. They describe and talk about the most common stereotypes, detecting the existing prejudices. They then ask the students different questions, first of all concerning their knowledge of disabled persons and then concerning their own beliefs about the issue, analyzing the stereotypes and prejudices that come up.

The second session consists of a hands-on modeling activity through a simulation of a disability, dividing the students into groups of five who then have to follow different paths using technical assistance (wheelchairs, crutches, walking sticks and masks). The monitors direct, support and advise the groups in the use of the said technical aids and in how to cope with the architectural and communication barriers that may be detected during the simulation. Later, using group dynamics, the monitors lead a discussion of all the groups together to analyze the experience and the difficulties found, empathizing with the disabled persons. Finally, the monitors talk about their experience concerning the difficulties they have to overcome in their own lives, not so much because of their disability, but because of a lack of respect for their rights which prevents them from carrying out many ordinary, daily activities and from exercising different roles in society.

In the third session, they work on a theme previously selected by the educational center from among several that are offered on the program (Equality, Bullying, Tolerance 
and Coexistence, Adapted Sport, The Environment and Recycling. The monitors introduce and explain the topic to be dealt with, and then divide the class group into teams which work on the main aspects of the subject using different materials. The monitors supervise the work of the teams and resolve doubts, guiding the class group as a whole. Each group then sets out their conclusions and closely monitors the session with a general conclusion relating the theme under discussion to universal rights and values and relating these to the different types of diversity that exist.

The third and last phase takes place two weeks after completing the intervention, with the application of the questionnaire CBAD-12A, in the same tutorial hour as in the first phase and in the same conditions.

For ethical reasons, once the research finished, the students in the control group were offered the opportunity to do the activities of the program under the same conditions as the experimental group.

\subsection{Design}

This study used a quasiexperimental methodology with an intergroup pre-test/posttest design and nonequivalent group control, where, although the centers and the groups were chosen at random, the participation of the students was not random as they were naturally constituted and could not be formed randomly, since the reality of the classroom and its conditions were to be maintained. The quasiexperimental methodology is one of the most commonly used methodologies in educational research. Quasiexperimental methods have taken on a great importance in most empirical studies carried out in the educational sphere due to the organizational and ethical difficulties involved and to the desire to effectively explain the cause-effect relationships of the said method. A quasiexperimental design consists in applying experimental designs to real situations (educational, family, social, etc.). However, it does have limitations. The experimenter cannot fulfill all the strict requirements of the experimental control: different values cannot be assigned to the independent variable at will and nor is it possible to randomly assign subjects to the different groups. The two fundamental strategies for alleviating these limitations are to include a control group and to take measures both before and after the application of the treatment.

The work was done with independent groups, an experimental group and a control group, made up of, respectively, 770 and 105 students from the four years of obligatory secondary education in the 20 participating centers. Belonging to the control or the experimental group was determined taking into account the ethical and organizational implications derived from the fact that in a particular center some class groups might intervene while others did not. Thus, the students of the control group belonged to a single center chosen at random. The experimental group received the intervention through a program to change attitude towards persons with a disability as opposed to the control group which did not receive the intervention. However, both the experimental and control groups completed a brief pre-test and post-test questionnaire (CBAD-12A [54]).

\subsection{Data Analysis}

Initially, reliability analyses were carried out (Cronbach's Alpha and McDonald's Omega) and confirmatory analyses of the instrument were used. Secondly, in order to determine the supposed normality and homoscedasticity, the data were subjected to the Kolmogorov-Smirnov and Levene tests. A $p>0.05$ was found in all the contrasts, thus justifying the use of the tests: the student $t$ test for independent but related samples and the covariance analysis (ANCOVA). We also used tests to measure the size of the effect (Cohen's $d$ and Hedges' $g$ ). The statistical techniques used were carried out with the SPSS statistical package, version 21 (IBM Corp, New York, NY, USA, 2012) and JASP Free (University of Amsterdam, Amsterdam, The Netherlands). 


\section{Results}

First of all, in order to discover whether the scores of the pre-test of the CBAD-12 A allowed an appropriate intergroup comparison base (control-experimental), thus reducing the possibility that the estimates associated to the independent variable could be due to other factors not taken into account and to contrast the efficacy of the intervention carried out, we made intergroup pre-test comparisons (control/experimental), as well as intragroup comparisons (pre-test/post-test) (Table 2). Similarly, to complete the information provided by the application of the significance tests (student $t$ test), the size of the effect was calculated using Cohen's $d$ and Hedges' $g$ statistics (Table 2).

Table 2. Differences between intra- and intergroup averages and size of the effect of the CBAD-12 A (control/ experimental groups).

\begin{tabular}{|c|c|c|c|c|c|c|c|c|c|c|c|c|c|c|c|c|c|c|c|c|}
\hline \multirow{3}{*}{$\begin{array}{l}\text { CBAD-12A } \\
\text { Factors }\end{array}$} & \multicolumn{7}{|c|}{ Experimental Group $(\mathrm{N}=770)$} & \multicolumn{7}{|c|}{ Control Group (N = 105) } & \multicolumn{6}{|c|}{ Control/ Experimental Group } \\
\hline & \multicolumn{2}{|c|}{ Pre-Test } & \multicolumn{2}{|c|}{ Post-Test } & \multicolumn{3}{|c|}{ Intragroup } & \multicolumn{2}{|c|}{ Pre-Test } & \multicolumn{2}{|c|}{ Post-Test } & \multicolumn{3}{|c|}{ Intragroup } & \multicolumn{3}{|c|}{$\begin{array}{c}\text { Pre-Test } \\
\text { Inter-Groups }\end{array}$} & \multicolumn{3}{|c|}{ Post-Test Inter-Groups } \\
\hline & M & SD & $\mathbf{M}$ & SD & $\mathrm{t}$ & $p$ & $d$ & M & SD & $\mathbf{M}$ & SD & $\mathrm{t}$ & $p$ & $d$ & $t$ & $p$ & $g$ & $t$ & $p$ & $g$ \\
\hline $\begin{array}{l}\text { F1: Acceptance } \\
\text { Rejection }\end{array}$ & 7.29 & 2.72 & 6.82 & 2.57 & 5.24 & $<0.001$ & 0.18 & 6.94 & 2.76 & 7.08 & 3.20 & -0.41 & 0.686 & 0.05 & -1.03 & 0.305 & 0.13 & 1.28 & 0.200 & 0.09 \\
\hline F2: Competence & 10.73 & 3.05 & 9.17 & 2.97 & 16.49 & $<0.001$ & 0.52 & 10.45 & 3.06 & 10.64 & 3.55 & -0.66 & 0.509 & 0.06 & -0.59 & 0.552 & 0.09 & 4.54 & $<0.001$ & 0.48 \\
\hline F3: Opportunity & 6.80 & 2.41 & 6.47 & 2.35 & 3.45 & 0.001 & 0.14 & 6.56 & 2.28 & 7.27 & 2.45 & -2.77 & 0.007 & 0.30 & -0.56 & 0.576 & 0.10 & 3.35 & 0.001 & 0.34 \\
\hline
\end{tabular}

The absence of significant differences $(p \leq 0.05)$ in the scores of the CBAD-12A, in the pre-test intergroup comparisons (control/experimental), show the equivalence between the groups as a basis for comparison (Table 2). On the other hand, in the post-test intergroup comparisons (control/experimental), the experimental group obtained significantly lower scores $(p<0.001)$ in the factors 2 (Competence) and 3 (Opportunity) of the CBAD-12A, with small and medium effect sizes $(g \geq 34)$ (Table 2).

Furthermore, to control possible variations due to differences between the control and the experimental groups, the data were subjected to the Student $t$ test for related samples (Table 2), contrasting whether the results found could be attributed to the independent variable (the intervention). In this sense, the intragroup comparisons show a significant reduction $(p<0.05)$ from the pre-test scores to the post-test scores for the experimental group in all three factors of the CBAD-12A, with small effect sizes $(d \geq 14)$ in the factors 1 (Acceptance/rejection) and 2 (Competence) and medium effect sizes $(d=52)$ in the factor 3 (Opportunity). On the other hand, within the control group, there was a significant increase $(p<0.05)$ between the pre-test and post-test scores in the factor 3 (Opportunity), with a medium effect size.

Finally, to eliminate the effect from the dependent variables (post-test scores of the CBAD-12A) that could be attributed to variables not included in the design and thus not subjected to experimental control and as a complement to the intra- and intergroup tests, intersubject effect tests were also carried out (ANCOVA). The pre-test scores of the dependent variables were used as covariables and the experimental/control groups of the intervention were used as the fixed factor (Table 2).

The ANCOVA (Table 3) shows significant differences $(p<0.05)$ between the groups (experimental and control) in the factors 1 (Acceptance/rejection), 2 (Competence) and 3 (Opportunity), confirming the results found in the intergroup comparisons (Table 2). Thus, the decreases observed in the scores of the CBAD-12A in the experimental group can be attributed to the intervention carried out. 
Table 3. Intersubject effects test (ANCOVA). Factors CBAD-12A/Intervention group.

\begin{tabular}{|c|c|c|c|c|c|c|c|}
\hline $\begin{array}{l}\text { CBAD-12A } \\
\text { Post-Test }\end{array}$ & Origin Pre-Test & $\begin{array}{l}\text { Sum of Type } \\
\text { III Squares }\end{array}$ & $G l$ & Quadratic Mean & $F$ & Sig. & $\eta^{2}$ \\
\hline \multirow{3}{*}{$\mathrm{F} 1$} & $\begin{array}{l}\text { F1. Acceptance } \\
\text { Rejection }\end{array}$ & 1800.852 & 1 & 1800.852 & 361.737 & $<0.001$ & 0.294 \\
\hline & Intervention Groups & 17.274 & 1 & 17.274 & 6.470 & 0.043 & 0.009 \\
\hline & Error & 4331.158 & 870 & 4.978 & & & \\
\hline \multirow{3}{*}{ F2 } & F2. Competence & 3108.150 & 1 & 3108.150 & 541.540 & $<0.001$ & 0.383 \\
\hline & Intervention Groups & 248.607 & 1 & 248.607 & 43.315 & $<0.001$ & 0.047 \\
\hline & Error & 5004.811 & 872 & 5.739 & & & \\
\hline \multirow{3}{*}{ F3 } & F3. Opportunity & 765.008 & 1 & 765.008 & 162.799 & $<0.001$ & 0.158 \\
\hline & Intervention Groups & 72.090 & 1 & 72.090 & 15.341 & $<0.001$ & 0.017 \\
\hline & Error & 4078.806 & 868 & 4.699 & & & \\
\hline
\end{tabular}

\section{Discussion}

The research we developed deals with the efficacy of a program to change attitudes towards persons with a disability among adolescent students. The intervention is based on structured contact, awareness raising and information and a simulation of disability.

In order to achieve our objectives in this work and to guarantee the generalization of our results, we first evaluated the reliability and validity of the instrument CBAD12A. The three related factors of the model of the said instrument used in the original study adequately fit our data. The indices achieve optimum values, evidencing sufficient reliability and validity for the generalization of our results [55].

We carried out an intergroup comparison (GC and GE) to check that the changes in the measurements obtained from the pre-test and post-test were due to the program and not to other factors. The equivalence of the two groups was verified with respect to the attitudes shown towards disabled persons.

Secondly, as our main objective, we analyzed the impact and influence of the Program for Changing Attitudes towards Disability (PCAD) on the students, starting from the hypothesis that there would be a decrease in the scores of the CBAD-12A in the GE but not in the GC, which would indicate an improvement in the attitudes of the students in the experimental category due to the effects of the program (to be precise, a decrease in the prejudices and stereotyping with respect to disabled persons and an improvement in their perception of the said collective's competence). To do so, after subjecting the data to the Student $t$ test for related samples, we demonstrated the efficacy of the intervention for the experimental group as we were able to attribute the changes in attitude to the effects of the program. To be precise, following the intervention, we found an improvement in the attitudes in all three factors of the CBAD-12A (Acceptance-rejection, Competence and Opportunity).

The improvements observed in the three factors reflect the fact that the students participating in the PCAD had modified their attitudes, in the sense that their acceptance towards disabled persons had increased, presenting a more competent view of the said collective and generating a greater respect towards their fundamental rights. In this sense, we believe that the structured contact with monitors with a disability, on the basis of a competence model, has generated sufficient cognitive dissonance in the students as to produce a re-evaluation of the dominant prejudices and stereotypes that they held prior to the intervention, changing their perception of persons with a disability. In this sense, the students show a greater acceptance of the collective and the adoption of a more competent view of disabled persons [36]. According to certain studies, these attitude changing programs can promote the development of a greater social conscience in adolescents, leading to a more intense social acceptance of disabled persons that breaks with the stereotypes and 
prejudices that exist towards them $[34,47,56]$. Furthermore, as the intervention includes a simulation of situations that imply a lack of respect for and violation of the fundamental rights of persons with a disability, such as a lack of accessibility, this generates within the students a greater sense of empathy with and sensibility towards the collective, which in turn is translated into the consequent change in attitudes towards them [57].

We did not find such a change in the control group; in fact, their attitudes worsened in all three factors of the CBAD-12A, as can be seen in the scores of the pre-test and the post-test, in particular in the significance of the factor opportunity. Thus, this confirms that the control group, on not receiving the intervention, maintained and even worsened their attitudes towards the collective due to the ignorance they still had concerning disabled persons, focusing their perceptions on aspects related to the limitations (social prejudices and stereotypes) and not on the possibilities, capacities and potential of persons with a disability [58].

Nevertheless, the significant differences found in the post-test scores between the experimental and control groups in all three factors of the CBAD-12A (Acceptance-rejection, Competence and Opportunity) reflect, with some certainty, that the PCAPD is effective in modifying negative attitudes towards disabled persons.

Similarly, the sizes of both the intragroup (pre-test/post-test) and intergroup (experimentalcontrol) effect indicate that the significant differences found are mostly small and medium: Small effect sizes $(d \geq 14)$ in the factors 1 (Acceptance/rejection) and 2 (Competence) and medium effect sizes $(d=52)$ in the factor 3 (Opportunity) with respect to the intragroup comparisons in the experimental group and medium effect sizes $(g \geq 34)$ in the factors Competence and Opportunity in the intergroup post-test comparisons (control/experimental). In the context of educational research, lower values than in other disciplines are usually found. When we are dealing with the application of innovative methodologies, values between $d=0.30$ and $d=0.33$ are considered to be relevant $[59,60]$. A medium value for the size effect of $d=0.40$ was found in an analysis of 500,000 interventions in an educational context [61].

The intervention carried out has facilitated the diffusion of the capacities of the monitors, persons with a disability, through positive interactions that allow a person's potential to be recognized, generating expectations that are more accurate and thus modifying attitudes towards them. The program carried out provides the students directly with information concerning the stereotypes that disabled persons suffer from, together with exposure to real situations that allow them to experience real situations that persons with a disability have to put up with in their daily lives. This type of intervention, based on structured contact with disabled persons, using a competent model that does not fit society's common stereotypes, allows one to know and get the feel of reality for a certain collective in a more accurate and realistic way. This provides more positive expectations, enabling more inclusive attitudes that eliminate barriers and prejudices, promoting a change of perspective based on inclusion and nondiscrimination $[11,25,35,36,48,49]$.

\section{Limitations and Future Lines of Research}

As a limitation of our study, we must first count those concerning the design of quasiexperimental studies themselves, derived from the fact that we are working with natural groups and are thus not able to assign the students who participate randomly into experimental or control groups; thus we do not have total control over the experimental variables and the results should therefore be interpreted with caution. On the other hand, another limitation of our study is how we follow the changes, as measurements of the program's effect over a longer period of time would be desirable in order to evaluate whether such changes are maintained. Nevertheless, despite the limitations, this type of research is a necessary resource that provides information in real life contexts, avoiding artificial situations.

Other limitations are related to the reliability values of the instrument and the exclusive use of self-report tests to gather information, as these are more subjective and 
there is the possible problem of bias due to social desirability, especially when evaluating sensitive subjects, as is the case here. In order to minimize the impact of this bias, in addition to distancing the application of the post-test by two weeks following the end of the intervention, confidentiality and anonymity were guaranteed by means of codes not connected to the names.

As future lines of research, we would consider relevant a more profound analysis of the differences in the effects of the changes in attitudes with respect to the different variables, such as the monitor (with or without a disability, type of disability), type of intervention and the different subjects dealt with, analyzing which are more effective in changing attitudes. We also consider that studies should be carried out to analyze the effects and consolidation of the changes over the long term.

\section{Conclusions}

The importance of bringing the reality of disabled persons to educational centers, to those at an age when negative attitudes towards the collective are still not consolidated, is fundamental for encouraging more positive views towards persons with a disability and for building a more inclusive society. This present study adds a valuable contribution to the sphere of inclusion. The results obtained make us optimistic concerning the achievement of a change in attitudes at a social level, beginning with schools, and more precisely, in our study, at the level of obligatory secondary education, which is a key moment in one's personal development and in the consolidation of one's attitudes. It is essential to direct actions and programs at educating students so as to understand and accept diversity and to respect the rights of everyone so they can enjoy equal opportunities if we wish inclusion to become a cornerstone of our society.

The technique of structured contact in this kind of program, bringing disabled persons center stage, has twofold benefits. On the one hand, the efficacy of this technique is confirmed in its ability to modify the attitudes of young persons and, on the other, it generates empowerment among the disabled persons who participate in the program as agents of change.

This type of program has a series of requisites that recommend its application. For instance, it is easy to include in the educational program of the centers, favoring the achievement of educational competences to be worked on in these years; then again, their cost/benefit and their results justify and encourage us to continue investigating through the study and implementation of these programs so as to enhance the inclusion of persons with a disability in society.

Author Contributions: Conceptualization, J.Á.-D., B.L.-d.-B., and M.-I.P.-d.-R.; Methodology, J.Á.-D., B.L.-d.-B. and S.M.-L.; Investigation, J.Á.-D., B.L.-d.-B., M.-I.P.-d.-R., V.-M.L.-R., S.M.-L.; Formal analysis, J.Á.-D., B.L.-d.-B., and S.M.-L.; Data curation, B.L.-d.-B., and S.M.-L.; Writing-original draft preparation, J.Á.-D., B.L.-d.-B., M.-I.P.-d.-R., and S.M.-L.; Writing—review and editing, J.Á.-D., B.L.d.-B., and M.-I.P.-d.-R. All authors have read and agreed to the published version of the manuscript.

Funding: This research received no external funding.

Institutional Review Board Statement: Not applicable.

Informed Consent Statement: Informed consent was obtained from all subjects involved in the study.

Data Availability Statement: Data is contained within the article.

Conflicts of Interest: The authors declare no conflict of interest.

\section{References}

1. Organización Mundial de la Salud. Informe Mundial Sobre la Discapacidad; Recuperado de. 2011. Available online: http: //www1.paho.org/arg/images/Gallery/Informe_spa.pdf (accessed on 12 March 2021).

2. Jiménez-Lara, A.; Huete, A.; Arias, M. Alumnado con Discapacidad y Educación Inclusiva en España; Observatorio Estatal de la Discapacidad: Madrid, Spain, 2019. 
3. Ley Orgánica 3/2020, de 29 de Diciembre, por la que se Modifica la Ley Orgánica 2/2006, de 3 de mayo, de Educación. Boletín Oficial del Estado, Número 340, (30 de Diciembre de 2020). Available online: https://www.boe.es/eli/es/lo/2020/12/29/3 (accessed on 12 March 2021).

4. Albrecht, G.L.; Seelman, K.; Bury, M. Handbook of Disability Studies; SAGE Publications, Inc.: Thousand Oaks, CA, USA, 2001.

5. Ferreira, M. Una aproximación sociológica a la discapacidad desde el modelo social: Apuntes caracteriológicos. REIS 2008, 124, 141-174. [CrossRef]

6. Hasler, F. El concepto de vida independiente a través de tres visiones: Filosófica, socio-política y económica. In El Movimiento de Vida Independiente. Experiencias Internacionales; Vidal, J., Ed.; Fundación Luis Vives: Madrid, Spain, 2003; pp. 55-76.

7. Martos, G.D.; Biassoni, P.D.; Torres, E.R.; Batista, L.S.; Hüg, M.X. Actitudes hacia la discapacidad en adolescentes: Efectos de un programa basado en el modelo social de discapacidad. Rev. Latinoam. Discap. Soc. Derec. Hum. 2019, 3, 70-88.

8. Schalock, R.L.; Verdugo, M.A. Calidad de vida: Manual Para Profesionales de la Educación, Salud y Servicios Sociales; Alianza: Madrid, Spain, 2003.

9. Abellán, A.; Hidalgo, R.M. Definiciones de discapacidad en España. Informes Portal Mayores. 2011, 109 , 2-17.

10. Organización Mundial de la Salud (OMS). Clasificación Internacional del Funcionamiento, de la Discapacidad y de la Salud; Grafo S.A: Madrid, Spain, 2001.

11. Organización de las Naciones Unidas (ONU). Convención Sobre los Derechos de las Personas con Discapacidad; Naciones Unidas: New York, NY, USA, 2006.

12. García-Fernández, J.M.; Inglés, C.J.; Vicent, M.; Gonzálvez, C.; Mañas, C. Actitudes hacia la discapacidad en el ámbito educativo a través del SSCI (2000-2011): Análisis temático y bibliométrico. Rev. Electrón. Investig. Psicoeduc. Psicopedag. 2013, 11, 139-166. [CrossRef]

13. Antonak, R.F.; Livneh, H. Measurement of attitudes towards persons with disabilities. Disabil. Rehabil. 2000, 22, 211-224. [CrossRef] [PubMed]

14. Martínez, M.; Bilbao, M. Los docentes de la universidad de Burgos y su actitud hacia las personas con discapacidad. Rev. Españ. Discap. Intelect. 2011, 42, 50-78.

15. Novo-Corti, I.; Muñoz-Cantero, J.M.; Calvo-Porral, C. Analysis of attitudes towards disability among university students: A focus on the theory of reasoned action. Rev. Electrón. Investig. Eval. Educ. 2011, 17, 1-26.

16. Zhang, H.N.; Xiao, F. Psychometric properties of the mental retardation attitude inventory-revised in Chinese college students. J. Intell. Disabil. Res. 2008, 52, 299-308.

17. Ovejero, A. Las Relaciones Humanas. Psicología Social Teórica y Aplicada; Biblioteca Nueva: Madrid, Spain, 1998.

18. González, M.; Leal, A. Los estudiantes con discapacidad entre los mitos, prejuicios y estereotipos. Rev. InterSedes 2009, 10, 118-129.

19. Rosenberg, M.J.; Hovland, C.I. Cognitive, affective and behavioral components of attitudes. In Attitude Organization and Change: An Analysis of Consistency among Attitude Components; Hovland, C.I., Rosenberg, M.J., Eds.; Yale University Press: New Haven, CT, USA, 1960.

20. Fondo de las Naciones Unidas para la Infancia. Niñas y niños con Discapacidad. Estado Mundial de la Infancia; UNICEF: Nueva York, NY, USA, 2013.

21. Sevilla, D.E.; Jenaro, C.; Druet, N.V. Formación Laboral como Proceso de Inclusión de Personas con Discapacidad Intelectual. En los Sujetos de la Educación Especial: Alumnos, Maestros y Autoridades; Investigación en México; Cárdenas Aguilar, T.J., y Barraza Macías, A., Eds.; Red Durango de Investigadores Educativos: Durango, México, 2014.

22. Shannon, C.D.; Schoen, B.; Tansey, T.N. The effect of contact, context, and social power on undergraduate attitudes toward persons with disabilities. J. Rehabil. 2009, 75, 11-18.

23. Hutzler, Y.; Zach, S.; Gafni, O. Physical education students' attitudes and selfefficacy towards the participation of children with special needs in regular classes. Eur. J. Spec. Needs. Educ. 2005, 20, 309-327. [CrossRef]

24. Vilchinsky, N.; Findler, L. Attitudes toward Israel's Equal Rights for People with Disabilities Law: A Multiperspective Approach. Rehab. Psychol. 2004, 49, 309-316. [CrossRef]

25. Rillotta, F.; Nettelbeck, T.E.D. Effects of an awareness program on attitudes of students without an intellectual disability towards persons with an intellectual disability. J. Intellec. Develop. Disabil. 2007, 32, 19-27. [CrossRef] [PubMed]

26. Suriá, R. Percepción del profesorado sobre su capacitación en el uso de las TICS como instrumento de apoyo para la integración del alumnado con discapacidad. Profesorado. Rev. Curríc. Form. Prof. 2011, 15, 299-314.

27. Vignes, C.; Godeau, E.; Sentenac, M.; Coley, N.; Navarro, F.; Grandjean, H.; Arnaud, C. Determinants of students' attitudes towards peers with disabilities. Dev. Med. Child Neurol. 2009, 51, 473-479. [CrossRef]

28. Allport, G.W. The Nature of Prejudice; Perseus Books: New York, NY, USA, 1979.

29. Abellán, J. Actitudes hacia la discapacidad, mostradas por los futuros maestros de Educación Física. Sportis Sci. J. 2015, 1, 207-219. [CrossRef]

30. Armstrong, M.; Morris, C.; Abraham, C.; Tarrant, M. Interventions utilising contact with people with disabilities to improve children's attitudes towards disability: A systematic review and meta-analysis. Disabil. Health 2017, 10, 11-22. [CrossRef]

31. Scanlon, G.; McEnteggart, C.; Barnes-Holmes, Y. Attitudes to pupils with EBD: An implicit approach. Emot. Behav. Diffic. 2020, 25, 111-124. [CrossRef]

32. Alcedo, M.A.; Gómez, L.E.; Aguado, A.L.; Arias, B.; González, R. Eficacia del contacto e información como técnicas de cambio de actitudes hacia personas con discapacidad en niños de Educación Primaria. Univ. Psychol. 2013, 12, 493-504. 
33. Verdugo, M.; Arias, B. Evaluación y modificación de las actitudes hacia minusválidos. Rev. Psicol. Gen. Appl. 1991, 44, 95-102.

34. Delgado, J.A. Estrategias psicosociales utilizadas para el cambio de actitud hacia las personas discriminadas por su discapacidad o trastorno mental. Rev. Esp. Discap. 2015, 3, 27-39.

35. Case, L.; Schram, B.; Jung, J.; Leung, W.; Yun, J. A meta-analysis of the effect of adapted physical activity service-learning programs on college student attitudes toward people with disabilities. Disabil. Rehabil. 2020, 20, 1-13. [CrossRef]

36. Polo, M.T.; Chacón-López, H.; Caurcel, M.J.; Valenzuela, B. Attitudes towards persons with disabilities by educational science students: Importance of contact, its frequency and the type of disability. Int. J. Disabil. Dev. Educ. 2020. [CrossRef]

37. Festinger, L.A. Theory of Cognitive Dissonance; Standford University Press: Standford, CA, USA, 1957.

38. González-Casas, D.; Ducca, L.; García-Román, C. La incidencia del apoyo social comunitario en la calidad de vida de personas con discapacidad. Siglo Cero Rev. Españ. Discap. Intelect. 2020, 51, 83-103. [CrossRef]

39. Laws, G.; Kelly, E. The attitudes and friendship intentions of children in United Kingdom Mainstream Schools towards peers with physical or intellectual disabilities. Int. J. Disabil. Develop. Educ. 2005, 52, 79-99. [CrossRef]

40. Polo, M.T.; Fernández, C.; Díaz, C. Estudio de las actitudes de estudiantes de Ciencias Sociales y Psicología: Relevancia de la información y contacto con personas discapacitadas. Univ. Psychol. 2011, 10, 113-123. [CrossRef]

41. Barroso, D.; Mendo, S. La relevancia de la formación y el contacto previo en la opinión de estudiantes universitarios sobre las personas con trastorno mental. Rev. Electron. Investig. Psicoeduc. Psigopedag. 2018, 16, 59-78.

42. Daruwalla, P.; Darcy, S. Personal and societal attitudes to disability. Ann. Tour. Res. 2005, 32, 549-570. [CrossRef]

43. Krahé, B.; Altwasser, C. Changing Negative Attitudes towards Persons with Physical Disabilities: An Experimental Intervention. J. Community Appl. Soc. Psychol. 2006, 16, 59-69. [CrossRef]

44. Chae, S.; Park, E.; Shin, M. School-based interventions for improving disability awareness and attitudes towards disability of students without disabilities: A metaanalysis. Int. J. Disabil. Dev. Educ. 2018, 66, 343-361. [CrossRef]

45. Cameron, L.; Rutland, A.; Turner, R.; Holman-Nicolas, R.; Powell, C. Changing attitudes with a little imagination: Imagined contact effects on young children's intergroup bias. Anal. Psicol. 2011, 27, 708-717.

46. Jeon, M. Meta-analysis of disability simulation researchfor elementary students in Korea. Internac. J. Spec. Educat. 2018, 33, 140-151.

47. Lindsay, S.; Edwards, A. A systematic review of disability awareness interventions for hildren and youth. Disabil. Rehabil. 2013, 35, 623-646. [CrossRef]

48. Díez, E.; Alonso, A.; Verdugo, M.A.; Campo, I.; Sancho, I.; Sánchez, S.; Calvo, I.; Moral, E. Espacio Europeo de Educación Superior: Estándares e Indicadores de Buenas Prácticas para la Atención a Estudiantes Universitarios con Discapacidad; INICO: Salamanca, Spain, 2011.

49. Nowicki, E. A cross-sectional multivariate analysis of children's attitudes towards disabilities. J. Intellec. Disabil. Res. 2006, 50, 335-348. [CrossRef]

50. Hodge, S.; Davis, R.; Woodard, R.; Sherrill, C. Comparison of practicum types in changing pre-service teachers' attitudes and perceived competence. Adapt. Phys. Activ. Q. 2002, 19, 155-171. [CrossRef]

51. McCarthy, J.; Light, J. Attitudes toward individuals who use augmentative and alternative communication: Research review. Augment. Altern. Commun. 2005, 21, 41-55. [CrossRef]

52. Morton, J.F.; Campbell, J.M. Information source affects peers' initial attitudes toward autism. Res. Dev. Disabil. 2007, 29, 189-201. [CrossRef] [PubMed]

53. Polo, M.; Heredia, C. Análisis de las Actitudes hacia la Discapacidad de la Familia en Educación Infantil. Rev. Educ. Inclus. 2020, 13, 75-91.

54. Álvarez, J.; León, B.; Polo, M.I.; Mendo, S. Questionnaire for Adolescents to Evaluate Their Attitudes towards Disability. Sustainability 2020, 12, 9007. [CrossRef]

55. Costello, A.B.; Osborne, J.W. Best Practices in Exploratory Factor Analysis: Four Recommendations for Getting the Most from Your Analysis. Pract. Assess. Res. Eval. 2005, 10, 1-9.

56. Aguado, A.L.; Flórez, M.A.; Alcedo, M.A. Programas de cambio de actitudes ante la discapacidad. Psicothema 2004, 16, 667-673.

57. Lopez-González, M.; López-González, M. Simular la discapacidad. Una técnica para conocer las necesidades educativas especiales y modificar actitudes en la formación del Profesorado. Rev. Elect. Interuniv. Form. Prof. 1997, 1. Available online: http:/ / www.uva.es/aufop/publica/actas/viii/aylee.htm (accessed on 12 March 2021).

58. Bausela, E. Actitudes hacia la discapacidad: Estudio de algunas propiedades psicométricas en una muestra de universitarios mexicanos. Rev. Iberoam. Educ. 2009, 49, 1-10. [CrossRef]

59. Borg, W.; Gall, J.; Gall, M. Applying Educational Research: A Practical Guide; Longman: New York, NY, USA, 1993.

60. Valentine, J.; Cooper, H. Effect Size Substantive Interpretation Guidelines: Issues in the Interpretation of Effect Sizes; What Works Clearing House: Washington, DC, USA, 2003.

61. Hattie, J. Visible Learning: A Synthesis of Meta-Analyses in Education; Routledge: London, UK, 2009. 